\title{
The effect of rollover footwear on pain, disability and lumbar posture in patients with low back pain
}

\author{
Atefe Rahimi ${ }^{1}$, Saeed Forghany ${ }^{1,2^{*}}$, Christopher Nester $^{2}$, Fateme pol ${ }^{1}$ \\ From 4th Congress of the International Foot and Ankle Biomechanics (i-FAB) Community \\ Busan, Korea. 8-11 April 2014
}

\section{Background}

Low back pain (LBP) is one of the most common musculoskeletal disorders [1]. Exercise therapy is often advised [2,3] but requires a significant time commitment, can rely on equipment or health professionals and risks low compliance. As an alternative or adjunct, shoes with a curved sole profile are thought to produce beneficial changes in ankle, knee, hip and back position and posture [4]. Therefore, the aim of this preliminary study was to investigate the effect of rollover footwear on pain, disability and lumbar posture in patients with lumbar pain.

\section{Material and method}

21 patients (age: $35.5 \pm 1.4$ years) with LBP (pain distal to the buttocks that centralized with extension) were randomly assigned to a rollover footwear and lumbar extension exercise group $(n=11)$ or a lumbar extension exercise only group $(\mathrm{n}=10)$. Baseline and 4 weeks post intervention measures were pain (visual analog scale), disability (Oswestry LBP disability) and lumbar posture when standing barefoot (as described by Forghany et al [4]).
Participants attended six appointments of 30 minutes duration over 4 weeks. Exercise consisted of 3 sets of 10 repetitions of extension exercises. Participants in the shoe and exercise group walked in rollover footwear [Perfect Steps] as often as possible over the 4 weeks (but at least 30 minutes each day).

\section{Results}

Participants in both groups showed significant decreases in pain levels and disability after four weeks. Participants in the shoe and exercise group had significantly greater decreases in pain $(\mathrm{p}=0.04)$ and demonstrated $11.8 \%$ greater reduction in disability, but this did not reach statistical significance $(p>0.05)$ (Table 1). The radius of lumbar curve was decreased in both groups when standing barefoot after 4 weeks, but not significantly $(p>0.05)$ and there was no significant difference in the change in the radius of lumbar curve between two groups ( $\mathrm{p}>0.05)$ (Table 1$)$.

\section{Conclusion}

This result suggests that the rollover footwear could be part of a treatment protocol for greater reduction in

Table 1 Mean and amount of change in pain, disability and lumbar posture in exercise only, and exercise and shoe groups.

\begin{tabular}{|c|c|c|c|c|c|c|c|c|c|}
\hline & \multicolumn{3}{|c|}{ Pain } & \multicolumn{3}{|c|}{ Disability } & \multicolumn{3}{|c|}{ Lumbar Posture (cm) } \\
\hline & Pretest & 4 weeks & change & Pretest & 4 weeks & change & Pretest & 4 weeks & change \\
\hline Exercise & $7.1 \pm 1.6$ & $4.8 \pm 2.1^{a}$ & $-\% 31.5$ & $36.9 \pm 10.5$ & $26.3 \pm 9.5^{a}$ & $-\% 27.8$ & $26.2 \pm 13.9$ & $22.2 \pm 10.5$ & $-\% 15.3$ \\
\hline Exercise + shoe & $7.3 \pm 1.8$ & $3.0 \pm 2.0^{a}$ & $-\% 58.9^{b}$ & $29.8 \pm 5.3$ & $18.0 \pm 5.9^{a}$ & $-\% 39.6$ & $20.1 \pm 11.9$ & $17.5 \pm 5.6$ & $-\% 12.9$ \\
\hline
\end{tabular}

${ }^{\mathrm{a}} \mathrm{P}<0.05$ (within group). ${ }^{\mathrm{b}} \mathrm{P}<0.05$ (between group).

\footnotetext{
* Correspondence: Saeed_forghany@rehab.mui.ac.ir

'Musculoskeletal Research Centre, Isfahan University of Medical Sciences, Iran

Full list of author information is available at the end of the article
} 
pain level in patients with LBP. However, the effects on lumbar biomechanics and association with changes in pain and disability remain unclear and requires further investigation.

\section{Authors' details}

${ }^{1}$ Musculoskeletal Research Centre, Isfahan University of Medical Sciences,

Iran. ${ }^{2}$ Centres for Health Sciences Research, University of Salford, UK.

Published: 8 April 2014

\section{References}

1. Dunsford A, Kumar S, Clarke S, et al: Integrating evidence in to practice: use of Mckenzie- based treatment for mechanical low back pain. J Multidiscip Healthc 2011, 4:393-402.

2. Peterson T, Larsen K, Jacobsen S: One-year follow-up comparison of the effectiveness of Mckenzie treatment and strengthening training for patients with chronic low back pain. J Spine 2007, 32:2948-2956.

3. Nigg B, Davis A, Lindsay D, Emery C: The effectiveness of an unstable sandal on low back pain and golf performance. Clin J Sport Med 2009, 19.

4. Forghany $S$, Nester $C$, Richards B: The relationship between sole curvature of roll over footwear and changes in gait. Foot Ankle 2012.

doi:10.1186/1757-1146-7-S1-A20

Cite this article as: Rahimi et al:: The effect of rollover footwear on pain, disability and lumbar posture in patients with low back pain. Journal of Foot and Ankle Research 2014 7(Suppl 1):A20.

\section{Submit your next manuscript to BioMed Central} and take full advantage of:

- Convenient online submission

- Thorough peer review

- No space constraints or color figure charges

- Immediate publication on acceptance

- Inclusion in PubMed, CAS, Scopus and Google Scholar

- Research which is freely available for redistribution

Submit your manuscript at www.biomedcentral.com/submit 